\title{
Significados e sentidos da formação de professores: um estudo das teses e dissertações defendidas na região Centro-Oeste ${ }^{1}$
}

\author{
Oliria Mendes Gimenes ${ }^{2}$ \\ omgudi@yahoo.com.br
}

\author{
Andréa Maturano Longarezi ${ }^{3}$ \\ andrea.longarezi@terra.com.br
}

\section{Resumo}

Neste trabalho, apresentam-se resultados de uma pesquisa desenvolvida em nível de mestrado que objetivou apreender o significado social das produções teóricas sobre formação de professores e o sentido pessoal atribuído e objetivado no contexto das teses e dissertações que desenvolveram pesquisas de intervenção nos Programas de Pós-Graduação em Educação na região Centro-Oeste. As análises empreendidas se pautam na categoria significado e sentido da teoria histórico-cultural, especificamente nos pressupostos de Vygotski e Leontiev. Na pesquisa, levantaram-se dados que permitiram observar que a coincidência ou não entre o que foi apropriado culturalmente pelos pesquisadores formadores de professores (significado) e

1 Investigação desenvolvida como subprojeto vinculado a pesquisas financiadas pelo CNPq e pela FAPEMIG.

2 Doutoranda em Educação pela Universidade de São Paulo (USP).

3 Doutora em Educação Escolar pela Universidade Estadual Paulista 'Júlio de Mesquita Filho'. Professora da Universidade Federal de Uberlândia. 
as práticas formativas propostas por eles nas pesquisas (sentido) revelam a concepção do pesquisador e seu processo formativo, pois se apropriou do significado e a ele atribuiu sentido. Concluímos que os processos mediacionais presentes na formação e prática docente são definidores da apropriação do significado social e da atribuição de sentido.

Palavras-Chave: significado e sentido, formação docente, teoria histórico-cultural

\title{
Meaning and sense of teacher's training: a study of thesis and dissertations defended in the center-west region
}

\begin{abstract}
This work presents the results of a research developed on master's degree, which aimed at apprehending the social meaning of theoretical productions about teacher's training and the individual sense aimed in the context of thesis and dissertations that developed researches of intervention in post-graduation programs in Education in center-west region. The analyses are based on the category of meaning and sense from the historical-cultural theory, specifically according to Vygotski and Leontiev. The research obtained data that allowed us to observe that either the coincidence or the non-coincidence between what was culturally appropriate by the teachers' trainers (meaning) and the formative practices proposed by them in the researches (sense) reveal the researcher's conception and his formative process, once he appropriated the meaning and attributed sense to it. We conclude that the mediate processes presented in both the teacher's training and his practice define the appropriation of the social meaning and the attribution of sense.
\end{abstract}

Keywords: meaning and sense, teacher's training, historicalcultural theory 


\section{Introdução}

A formação de professores tem sido objeto de interesse de várias pesquisas de intervenção que vêm sendo desenvolvidas em nível de mestrado e doutorado. Essas pesquisas intervêm nos contextos, propondo processos formativos a partir de diferentes abordagens (concepções e práticas) de formação de professores.

Esses estudos, em tese, apoiam-se nessas perspectivas teóricas (que possuem uma significação definida socialmente) e as convertem em práticas de formação (que expressam os sentidos atribuídos pelos pesquisadores no processo de apropriação das abordagens sobre formação docente).

Sob essa premissa, apresentamos os resultados de uma pesquisa em que se objetivou apreender o significado social das produções teóricas sobre formação de professores e o sentido pessoal atribuído e objetivado no contexto das teses e dissertações que desenvolveram pesquisas de intervenção nos Programas de Pós-Graduação em Educação (PPGEDs) na região Centro-Oeste, de 1999 a 2008. O corpus de estudo é composto de nove trabalhos: uma tese da Universidade Federal de Goiás (UFG), duas dissertações da Universidade Federal de Uberlândia (UFU) e seis dissertações da Universidade de Uberaba (UNIUBE) ${ }^{4}$.

Optou-se por uma metodologia de pesquisa qualitativa mediante uma abordagem dialética na análise dos dados, sendo que foram adotados dois procedimentos metodológicos: um para coleta e tratamento de dados e outro para a análise.

No primeiro, utilizou-se o software Wordsmith Tools (SCOTT, 2008), apropriado da linguística de corpus como um recurso tecnológico, que foi empregado para a categorização informatizada. No segundo, foram tomados como unidades de significação, os clusters, relativos às perspectivas de formação, analisados sob a ótica da teoria histórico-

\footnotetext{
4 As instituições UFU e UNIUBE fazem parte da região sudeste conforme a CAPES. No entanto, existe uma ressalva declarada pela Coordenadora da Área de Educação de que os Programas de Pós-Graduação dessas instituições, em comum acordo com a CAPES, encontram-se alocados na região Centro-Oeste por estarem melhor integrados nessa região, beneficiando-se também com programas de recursos prioritários destinados as duas regiões.
} 
cultural, especificamente, a categoria significado e sentido, sendo eles: "professor competente" e "competência técnica" (racionalidade técnica); "reflexão sobre a prática" e "professor reflexivo" (racionalidade prática); "reflexão crítica" e "professor crítico/criativo" (intelectual crítico); “transformação social” e "catarse" (perspectiva histórico-crítica); "zona de desenvolvimento proximal" e "teoria da atividade" (perspectiva histórico-cultural); e "formação continuada de professores em serviço" e "formação em serviço" (formação por coletivos).

Propomos articular o conteúdo das pesquisas às perspectivas de formação sob a luz desse referencial. Para isso, procuraremos expor como os clusters das perspectivas foram empregados nas pesquisas analisadas, de modo a apreender qual o significado e o sentido dado a elas pelos pesquisadores.

De posse dos dados sistematizados, a análise empreendida retrata as apropriações e objetivações dos processos formativos presentes nas pesquisas analisadas, a partir da análise dos clusters referentes às perspectivas de formação de professores, aos teóricos utilizados e às práticas formativas propostas pelos autores das pesquisas.

\section{Professor competente e competência técnica}

A forma com que os clusters "professor competente" e "competência técnica" surgem nos textos analisados está mais como crítica a esse modelo do que como adesão, e indica que os pesquisadores estão preocupados em censurar uma perspectiva de formação que desconsidera elementos importantes em detrimento a outros já superados, mas que ainda se encontram presentes no âmbito da formação.

Os clusters nos trabalhos se apresentaram como citações e críticas, existindo indícios de influência da abordagem na constituição de seus autores, ou seja, o discurso presente nas pesquisas está impregnado de uma "significação a qual é concebida como a produção material, de natureza social, de signos e sentidos." (SMOLKA; LAPLANE, 2005, p. 79).

Além dessas características apresentadas, há ocorrências em que a palavra se apresentou no histórico do campo investigativo, sustentando 
o surgimento desta, como consta em um fragmento contido na contextualização do campo da pesquisa, sinalizando que a autora coaduna com a ideia de que uma instituição de ensino profissionalizante deve ter o conceito de competência como slogan de sucesso em uma sociedade.

Contudo, não há ligação de autores da perspectiva de formação com base na racionalidade técnica presente nos trabalhos analisados, mas, existe a presença de teóricos ligados ao conceito de competências do professor.

Embora os autores Rios (2001), Tardif e Lessard (1991), Tardif (1993, 1999, 2002), Perrenoud (1997, 1999, 2000, 2001) e outros tenham sido citados de modo significativo quando estavam em pauta, o professor competente e a competência técnica, clusters representativos da racionalidade técnica, não estão ligados a essa perspectiva de formação. Entretanto, os conceitos sobre competências por eles difundidos, em nossa sociedade, permitiram que os autores dos trabalhos analisados se apropriassem e atribuíssem sentidos a partir de seus contextos, como no trabalho UNIUBE-2.

O contexto em que foi realizada essa pesquisa reflete a essência da perspectiva da racionalidade técnica, pois se trata de uma escola profissionalizante, criada na ditadura, carregada de conceitos e práticas educativas voltadas para o mercado de trabalho, visando a atender à sociedade capitalista.

Dois clusters, no mesmo fragmento, estão presentes com significados distintos: "professor competente" aliado a trabalho de qualidade, e "formar em serviço" ligado a uma formação em conjunto com outros professores. Elas se referem a abordagens distintas, não se admitindo, de acordo com os significados construídos historicamente, a permanência dessas abordagens de maneira harmoniosa.

Chama a atenção o fato de a autora acreditar que os superiores na figura do gerente e/ou supervisores - palavras bem características da racionalidade técnica - têm como função dentro da instituição não a mediação, mas sim o apoio/suporte para que nada seja empecilho à sua eficiência.

Entretanto, ao mesmo tempo, acredita ser na formação em serviço que o instrutor terá êxito na função de ensinar. Por ela estar em conjunto com todos os professores, propicia um aprendizado a partir de um objetivo 
comum, no local de trabalho, todos se ajudando mutuamente, sendo que essas características são insuficientes diante do que foi construído socialmente na perspectiva de formação por coletivos, não podendo, assim, estar relacionada a essa abordagem, mesmo que a prática formativa proposta tenha valorizado cada participante.

Em relação ao cluster "competência técnica", este se apresenta como forte crítica à perspectiva da racionalidade técnica, que esteve presente no meio educacional por longo tempo, influenciando não só os docentes, como também os discentes.

As críticas empreendidas no trabalho UNIUBE-5 são contundentes, indo desde as características das primeiras escolas normais até uma linha temporal sobre a formação de professores no Brasil.

Tendo em vista o teor político do trabalho UNIUBE-5, esse não deixa de fazer menção às políticas públicas de educação, ficando claro que o cluster está significando a intencionalidade das políticas públicas governamentais ao relacionarem os resultados das avaliações institucionais à atuação do professor, atribuindo o rendimento de seus alunos à sua competência técnica. No trabalho UNIUBE-2, a competência está relacionada aos documentos oficiais regulamentadores da educação brasileira.

O trabalho UNIUBE-5 interveio junto aos gestores escolares a partir de um curso de extensão em parceria com uma instituição superior de ensino, versando sobre a gestão escolar da formação continuada de professores em serviço.

O trabalho UNIUBE-6, que versa sobre as práticas desportivas, por sua vez, critica a racionalidade técnica como pressuposto de formação de professores, sendo que nos esportes coletivos, ela ainda predomina, mesmo porque, no meio esportivo estão presentes as técnicas específicas de cada esporte.

\section{Reflexão sobre a prática e professor reflexivo}

Os clusters "reflexão sobre a prática" e "professor reflexivo" são características da perspectiva de formação com base na racionalidade prática, a qual preconiza que o professor, ao refletir sobre e na ação, num 
movimento de reflexão-ação-reflexão e valorização de suas experiências, ampliará a sua atuação como profissional, no sentido de ir além das teorias.

O emprego desses clusters no âmbito das pesquisas analisadas não só se refere à perspectiva da racionalidade prática, como também à própria acepção da palavra refletir. Elas estiveram presentes em instrumental de coleta de dados, questionando se a prática formativa favoreceu a reflexão sobre a prática pedagógica dos sujeitos, bem como em citações diretas e indiretas.

Está claro como o autor da pesquisa UFU-2, ao acompanhar um grupo de estagiários do curso de Matemática em uma escola pública, percebeu a necessidade de uma reflexão sobre a realidade escolar, confirmando que o ambiente real de atuação do futuro professor contém elementos que extrapolam a formação inicial.

A preocupação demonstrada pelo pesquisador se encontra permeada de aspectos ligados à abordagem da racionalidade prática, pois afirma ser a reflexão sobre a prática a única ação formativa do professor, delegando a apenas esse movimento individual e sem instrumentalização de nenhuma ordem (teórica, disciplinar, política) a responsabilidade de fazer com que o professor modifique sua prática.

Os autores citados, Freitas (1995,2000), Pimenta (1998, 1999, 2002), Vasconcellos (1998, 1999, 2000, 2001), André (1995, 2000), Pereira (2000), Alvarado Prada (1997, 2002, 2005, 2006), Freire (1979, 1987, 1992, 1999, 2000) e outros, não estão aliados à perspectiva da racionalidade prática em si, e sim aderentes a outras abordagens; porém, eles acreditam, sim, que a ação de refletir junto a um coletivo permite a construção de uma base para o processo de transformação, gerando uma revolução ${ }^{5}$ como defendida por Marx.

Apreende-se, pois, que em muitos desses casos a utilização desses autores ocorre pelo simples fato de que eles defendem a reflexão. Contudo,

\footnotetext{
5 Marx se inspira nas descrições e projeções históricas das revoluções francesa, inglesa e norte-americana para conceituar revolução. A revolução somente ocorre quando há uma ruptura com a velha ordem política, social e econômica; e em seu lugar são estabelecidos novos padrões de relações sociais que têm por princípio assegurar a liberdade e a igualdade social entre os homens. Em geral, é violenta, pois mexe com o ordenamento já estabelecido. Assim, Marx não entende a revolução como reconstrução da sociedade a partir do zero, mas acredita que o novo é sempre gestado tendo o velho por ponto de partida (MARX; ENGELS, 1989).
} 
a fazem sob a base de outra significação, de um referencial marxista, de transformação da realidade como ruptura, não da maneira como a reflexão é proferida nas bases da perspectiva da racionalidade prática.

Existem fragmentos que ilustram como os autores dos trabalhos analisados se sustentam em teóricos que versam e refletem sobre a prática, retratando que esse é o fio condutor da atuação do professor e o responsável pela construção do ser docente, bem como de seu desenvolvimento profissional.

A autora do trabalho UNIUBE-5, na parte introdutória de sua pesquisa, expressa que, ao tomar contato com as ideias defendidas pelo teórico da abordagem de formação por coletivos, Alvarado Prada (2006), conseguiu superar os problemas existentes em seu contexto a ponto de transformar a realidade do seu grupo.

Nessa parte existe uma confluência de concepções, a de formação por coletivos e a da racionalidade prática, pois a autora se refere aos conhecimentos adquiridos sobre a formação continuada em serviço proposta por Alvarado Prada, como sendo desveladores de sua problemática, entretanto, afirma que a reflexão sobre a sua prática, como partícipe daquele contexto, contribuiu para a sua superação diante das situações-problema.

Contudo, a autora em certa passagem se utiliza de vários conceitos referentes às duas perspectivas de formação, por coletivos e racionalidade prática no mesmo parágrafo, ou seja, ela direciona "aproximação entre a ciência e o cotidiano"; "relação teoria-prática"; " por meio da pesquisa"; "reflexão sobre a minha prática"; "coletivo"; "superar situaçõesproblemas"; e "transformação da realidade", de forma indistintamente.

No espaço do trabalho UNIUBE-3, que indica a utilização da abordagem de formação por coletivos a partir dos pressupostos da pesquisa coletiva, está claro diante do conteúdo de um de seus capítulos, no tocante à exposição da trajetória da formação de professores, que os ideários do professor reflexivo de Schön foram influenciadores de novas propostas de formação, inclusive a que ela é defensora, pois também pratica a reflexão sobre a prática.

Os conceitos do professor reflexivo, bem como a reflexão sobre a 
prática, sustentam o discurso educacional; no entanto, os princípios desses fazem parte da vida humana, pois, segundo a autora do trabalho UNIUBE-3, estão ligados aos princípios do refletir para agir de forma autônoma e ao aprender a aprender. Esse se constitui em um pressuposto de que o aprender sozinho é mais importante e significativo do que o aprendizado realizado entre pessoas.

De outra maneira, o modelo de formação baseado no professor reflexivo está aderente no trabalho UFU-1, quando a pesquisadora anuncia ser esse paradigma o referencial de sua pesquisa, como consta o conteúdo de seu segundo capítulo.

Sua proposta de prática formativa esteve presentenos acompanhamentos, ora individualizado ora em duplas, momentos em que a pesquisadora se utilizava dos princípios do desenvolvimento pessoal e profissional, incentivando uma postura crítica e reflexiva e, para tanto, apoiou-se em teóricos como Silva et al. (2002) e outros, contudo, admite desconhecer o motivo da não mudança nas práticas educativas após o grupo refletir sobre elas.

\section{Reflexão crítica e professor crítico/criativo}

De maneira semelhante ao cluster "reflexão sobre a prática", o cluster "reflexão crítica" também esteve inserido nos trabalhos analisados. Apresentou-se de forma genérica, mas se mantendo muitas vezes ao lado de questões políticas.

Nos trabalhos analisados, o cluster "reflexão crítica" se apresentou com uma frequência superior ao "professor crítico/criativo", em forma de citações e falas dos sujeitos envolvidos, não havendo passagens com críticas à abordagem, sendo que a mesma apresentação esteve presente para "professor crítico/criativo".

Alertamos quanto à aparição de Freire (1999) e André (2000) como suporte de ideias sobre reflexão crítica, sendo que eles também apareceram sustentando conceitos de reflexão sobre a prática. Nesse caso, como no anterior, esses autores não se aderem à perspectiva de formação com base no intelectual crítico, mesmo tendo sido feitas aproximações 
pelos pesquisadores, no que diz respeito à reflexão crítica. No entanto, as bases epistemológicas não são coincidentes.

No sentido de ir para além do campo da escola, em um dos trabalhos (UNIUBE-1), a pesquisadora afirma que sua proposta vai além da análise da realidade escolar e demonstra sua preocupação diante das práticas empreendidas sobre avaliação da aprendizagem, quando registra que o estudo a que se propõe ir para além da simples descrição e análise da realidade escolar. Nesse mesmo trabalho, a parte introdutória já anunciava essa proposição afirmando ser uma formação continuada em serviço a partir da reflexão crítica.

Na passagem, percebemos a presença de uma expressão-chave da perspectiva de formação por coletivos atrelada à "reflexão crítica", ou seja, existe dentro de uma proposta de formação continuada dentro do próprio local de trabalho, permeada de ações geradoras de reflexões críticas e coletivas.

Ligada à perspectiva do intelectual crítico aparecem, por exemplo, as concepções de "professor crítico" e/ou "professor criativo"; às vezes, apresentando os dois adjetivos juntos para qualificar o professor. Nessa perspectiva, o professor tem de se portar como intelectual, ou seja, compreende-se que o professor como intelectual usará de sua criatividade para trabalhar o que perpassa no currículo oculto.

No trabalho em que foi realizado o acompanhamento de estagiários, ou seja, futuros professores de matemática (UFU-2), em que se utilizou da informática para ensinar conteúdos de uma ciência "dura", o pesquisador se preocupa com a ausência das Tecnologias da Informação e Comunicação (TICs) nos currículos da formação inicial de forma integrativa, quando dialoga com Matos (2004) sobre a questão da utilização da informática na educação.

Nesse sentido, o pesquisador do trabalho UFU-2 aproveitou a experiência que os estagiários tiveram durante uma das disciplinas do curso de licenciatura de Matemática, em que usaram software para auxiliar nas atividades do curso, acreditando ser a informática um dos elementos necessários para o dinamismo das aulas a partir da criatividade do professor, principalmente o de Matemática. 
A autora da pesquisa UNIUBE-4, ao fazer uma reflexão sobre a ação educativa, a faz indo além do espectro do professor e considerando o aluno como parte do sucesso do processo. Diferentemente da passagem anterior, nessa a autora coloca o aluno a frente do processo, afirmando que ele aprende se os saberes transmitidos pelo professor forem significativos para ele.

A prática formativa proposta no trabalho UNIUBE-4 promoveu encontros com o grupo visando à formação continuada de professores de escolas localizadas em um assentamento. Os encontros tinham como base dinâmicas que levavam à reflexão seguida de registros escritos, sendo que cada um desses era sobre uma temática, proveniente do questionário inicialmente aplicado ao coletivo, levando em conta a diversidade cultural do contexto pesquisado.

\section{Transformação social e catarse}

Os clusters "transformação social" e "catarse" estão relacionados à perspectiva histórico-crítica de Saviani (2005), em que ele elabora uma tendência pedagógica crítica e articuladora dos condicionantes sociais, visando a superar a teoria reprodutivista daquele momento.

Essa teoria foi sistematizada em uma didática proposta por Gasparin, a partir de cinco procedimentos metodológicos: prática social inicial, problematização, instrumentalização, catarse e prática social final.

O trabalho UNIUBE-1 foi o único a apresentar o cluster "catarse", sendo que "transformação social", embora também presente nesse trabalho, ocorreu nos trabalhos UFG-1, UNIUBE-3, UNIUBE-4, UNIUBE-5 e UNIUBE-6, ligada não aos pressupostos da perspectiva histórico-crítica, mas a questões de mudanças no contexto social e/ou como consequência da metodologia de pesquisa-ação. Elas se apresentam em grande parte como citações.

Conforme enunciado pelos fragmentos dos trabalhos, "transformação social" em dois deles (UFG-1 e UNIUBE-3), está ligada à metodologia de pesquisa, atribuindo à pesquisa-ação uma característica de transformação que ocorre no contexto em que ela é realizada. 
No trabalho UNIUBE-4, o atributo ao cluster se refere à inovação do currículo escolar das escolas rurais como sendo um ponto importante de reconhecimento de uma postura política visando à transformação do contexto social em que elas estão inseridas.

Mazzeu (1998) é o único teórico que aborda o cluster com aderência à perspectiva histórico-crítica, sendo que os demais citados versam sobre transformação social com outras significações, distantes da perspectiva, como Thiollent (2007) e Ponte (2005), que serviram de apoio para referendar a pesquisa-ação como meio de transformação.

Não obstante, o cluster "transformação social" ocorreu como crítica às políticas públicas em vigor, chamando a atenção do que subjaz ao discurso de formação para a transformação, ou ainda, em um ideário de apenas modificar o que está posto.

Em uma das passagens do trabalho UNIUBE-3, a autora diz que a transformação está presente apenas no discurso político e que devemos analisar cuidadosamente suas partes e seus relacionamentos dentro do todo. Entretanto, ela se utiliza da palavra progresso aliada à transformação que se torna incoerente com a perspectiva histórico-crítica, pois progresso está associado à ideia de evolução, sem haver uma ruptura com o que está posto e, assim, não sendo pertinente à abordagem. Não há aqui, pois, coincidência entre o significado social apreendido no contexto da perspectiva históricocrítica e o sentido pessoal atribuído pela pesquisadora.

Em relação ao proclamado pelas políticas públicas, um dos trabalhos (UNIUBE-4), em que a pesquisadora interveio em escola pública de um assentamento, promovendo uma formação baseada em oficinas, contemplando a pluralidade cultural existente naquele contexto, prega o combate ao modelo educativo existente combatendo a exclusão social a partir do comprometimento com a luta contra as desigualdades sociais e econômicas, provendo transformação social.

Um fragmento oriundo do trabalho UNIUBE-1, apresentado como citação de Alvarado Prada (1997), contém, além do cluster "transformação social", o "formação continuada [de professores] em serviço". Esse mesmo trabalho apresenta várias passagens em que o cluster "catarse", relaciona-se à perspectiva histórico-crítica com uma denotação específica 
e se apoia em autores que coadunam com ela.

A prática formativa realizada pelo trabalho UNIUBE-1 partiu da prática social que era realizada na escola, no que se refere à avaliação da aprendizagem, para, em seguida, problematizá-la a partir de discussões geradas pelo grupo de estudo realizado com reuniões periódicas no local de trabalho.

\section{Zona de desenvolvimento proximal e teoria da atividade}

Alguns clusters da perspectiva histórico-cultural se mostraram presentes nos trabalhos analisados, entretanto, "zona de desenvolvimento proximal" e "teoria da atividade" se apresentaram com ocorrências em forma de citações e notas de rodapé, no sentido de esclarecer conceitos e, de declaração de sustentação da pesquisa, respectivamente.

Três trabalhos apresentaram o cluster "zona de desenvolvimento proximal" e, apenas um, "teoria da atividade", sendo UFU-1, UFU-2, UNIUBE-1 e UNIUBE-6, respectivamente.

No caso do trabalho UNIUBE-6, o autor propôs um grupo de estudo para promover a formação de professores de esportes coletivos, preocupando-se com a necessidade que emanava do próprio coletivo, a qual estava aliada com os motivos que sustentavam a busca em alcançar os objetivos dessa formação. Assim, de acordo com o enunciado, sustentou-se na teoria da atividade.

Os demais que apresentaram o cluster "zona de desenvolvimento proximal" expressaram ser essa categoria importante para o processo de ensino, não podendo o professor ficar alheio a ela, mas, de acordo com o que foi enunciado, notamos uma interpretação enviesada do que fora proposto pela teoria histórico-cultural, inclusive associando Vygotski aos sociointeracionistas.

Algumas passagens dos trabalhos analisados em que continha o cluster demonstram que os pesquisadores se apoiaram em estudiosos que trataram do conceito desenvolvido por Vygotski para fundamentarem suas concepções e práticas, nem sempre apropriados de maneira correta, dados os inúmeros problemas de tradução que distorceram em muitos 
aspectos a teoria.

No fragmento do trabalho UFU-1, a autora se alia a um referencial teórico que coloca Vygotski nessa categoria, sendo que em suas obras, em nenhum momento existe essa denominação.

Em uma passagem do trabalho UNIUBE-1, a autora dialoga com um autor que admite ser a Zona de Desenvolvimento Proximal (ZDP) uma revolução no conceito de avaliação, relacionando-a a uma forma de testar a aprendizagem do aluno a partir das provas escolares.

Entretanto, Vygotski desenvolveu o conceito de ZPD relacionando-o com o desenvolvimento psíquico do homem, a partir da aprendizagem, sempre acreditando no campo das possibilidades e levando em consideração a mediação como elemento fundamental do processo, que é diferente do enunciado no fragmento, pois está relacionado à avaliação no formato de provas escolares, as quais preconizam apenas testar os conhecimentos transmitidos.

Em outro fragmento, no mesmo trabalho, a autora se apoia na ideia de que o indivíduo percorre um caminho para desenvolver suas funções superiores que estão em processo de amadurecimento e que virão a se tornar reais e, ainda, a ZDP está em constante transformação.

No trabalho UFU-1, em um fragmento, a pesquisadora acredita que os níveis da zona de desenvolvimento proximal podem ser medidos, a partir da solução de problemas. No entanto, o nível referenciado por Vygotski não coincide com o descrito pela autora.

Os sentidos atribuídos pela autora do trabalho UFU-1 ao conceito de zona de desenvolvimento proximal e aos níveis de desenvolvimento não são coincidentes com o significado construído pela teoria histórico-cultural.

Quando a autora anuncia que o nível de desenvolvimento potencial pode ser medido, fica clara a aproximação com as ideias difundidas sobre classificação e rotulação de crianças com QI baixo ou elevado, pois não está em conformidade com a abordagem em questão.

A partir dos conceitos apresentados nos trabalhos e ao que foi proposto como prática formativa pelos pesquisadores, percebemos que as oficinas e acompanhamentos, bem como o grupo de estudo, previa intencionalmente a existência, no momento da formação, de trocas 
de saberes e experiências, a ajuda do companheiro do grupo, além de discussões pautadas em interesses comuns.

Tudo isso, na idealização dos pesquisadores, remetia a uma ação na zona de desenvolvimento proximal de cada um dos integrantes, como propulsora de novas aprendizagens, como atesta a autora do trabalho UNIUBE-1.

Um dos trabalhos analisados (UNIUBE-6), o único a apresentar o cluster "teoria da atividade", uma teoria específica da perspectiva histórico-cultural, que concebe a atividade humana como importante elemento para o desenvolvimento humano, se apoia em autores como Leontiev (1978), Heller (2004), Makarenko (apud Capriles, 1993) e Alvarado Prada (2006).

Dentre o rol de autores indicativos da perspectiva histórico-cultural, salientamos que Alvarado Prada aqui aparece como sustentáculo dos pensamentos dos autores dos trabalhos analisados, ficando claro que foi escolhido por discorrer sobre elementos que se aproximam, em alguns aspectos, da teoria histórico-cultural, mas não se constitui como tal.

Essa aproximação é percebida quando, por exemplo, o autor do trabalho UNIUBE-6 descreve quais conceitos irá se apropriar durante sua pesquisa para fundamentá-la: teoria da atividade, de Alexis Leontiev; teoria do cotidiano, de Agnes Heller; coletivo de Makarenko; confronto de saberes, de Alvarado Prada; e teoria da ação comunicativa, de Jürgen Habermas.

A prática formativa proposta por esse trabalho se concretizou a partir da constituição de um grupo de estudos em esportes coletivos, no âmbito de uma instituição de ensino superior, composto por alunos do curso de licenciatura em Educação Física e profissionais externos que atuam com esse tipo de esporte. Esse grupo, por um determinado período, a partir do envolvimento de todos, promoveu uma formação a partir das necessidades teórico-metodológicas do próprio coletivo.

\section{Formação continuada de professores em serviço e formação em serviço}

Os clusters "formação continuada de professores em serviço" e "formação em serviço" pressupõem ser uma formação que envolve um coletivo, fazendo parte da perspectiva de formação por coletivos. 
O conceito de coletivo para essa abordagem define que ele é constituído por um conjunto de pessoas, com características diversas, com relações instituídas no próprio local de trabalho, mediante ações e objetivos, bem como de elementos políticos e sociais (ALVARADO PRADA, 2006). Nessa perspectiva, não corresponde a um agrupamento de pessoas, necessita, pois de se constituir mediante interesses, necessidades e projetos comuns. Dessa forma, o conceito de coletivo tem um papel fundamental e, portanto, uma significação própria. Não pode, então, ser confundido como os sentidos geralmente a ele atribuídos.

Os dois clusters ocorreram na forma de notas de rodapé, em falas dos sujeitos, citações diretas e indiretas, entretanto, destacamos o trabalho UNIUBE-5, pelo fato de que "formação continuada de professores em serviço" se apresenta com 104 ocorrências.

Nesse mesmo trabalho, o cluster "formação em serviço" se apresenta com 15 ocorrências, sendo que essa pesquisa promoveu uma intervenção que tinha como foco a formação em serviço de professores da rede municipal.

Percebemos que a pesquisa desenvolvida pela autora do trabalho UNIUBE-5 esteve envolvida de maneira relevante no que diz respeito à formação continuada de professores em serviço, demonstrando sua preocupação com a causa e, de certa forma, discorrendo ao longo de seu trabalho, de forma enfática, sobre o cluster em comento.

Os trabalhos em que ocorreu o cluster "formação em serviço" se apoiaram em teóricos de diversas vertentes, não sendo eles, aderentes necessariamente à perspectiva de formação por coletivos.

Dentre os teóricos citados direta ou indiretamente, Alvarado Prada $(1997,2002,2005,2006)$ foi o mais citado, demonstrando uma coerência em suas ocorrências entre o que ele defende e a forma com que a citação escolhida se adere ao sentido atribuído nos trabalhos em que ele se apresenta.

Contudo, os demais autores utilizados discutem a formação em serviço, criticando as políticas públicas e indicando como aquela necessita ser; no entanto, pertencerem a abordagens diversas. Observou-se, pois, um distanciamento entre as suas bases epistemológicas e a da perspectiva 
de formação por coletivos.

O único teórico citado para referenciar o cluster "formação continuada de professores em serviço" foi Alvarado Prada (1997, 2005b), com sete citações em um único trabalho, UNIUBE-5. O que, no nosso entendimento, revela que esse cluster tem uma significação tão particular que parece não ter sido ainda apropriado de forma genérica e independente de sua base epistemológica.

O trabalho UNIUBE-5 discute a proposta de um curso de gestão escolar da formação continuada de professores em serviço, que foi objeto da pesquisa com a pretensão de institucionalização de uma proposta de formação continuada como política pública municipal.

Nesse sentido, a pesquisadora do trabalho UNIUBE-5 se apoia em Alvarado Prada (1997, 2002, 2005a, 2005b, 2005c, 2005d, 2005e) para sustentar os seus pensamentos sobre formação continuada de professores em serviço. Esse teórico da perspectiva de formação por coletivos foi citado nesse trabalho 109 vezes, indicando haver uma sintonia entre a concepção da autora do trabalho e esse referencial.

A prática formativa desenvolvida pelo trabalho UNIUBE-5 surgiu da intencionalidade da pesquisadora, quando assessorava o projeto escolar de formação continuada: "desse modo, de janeiro a maio de 2005, participei da equipe que acompanhava e assessorava o Projeto Escolar de Formação Continuada de Professores em Serviço da Rede Municipal de Ensino de Uberaba - MG." (UNIUBE-5, 2006, p. 13).

Nessa perspectiva, a intencionalidade não pode ser exclusivamente de uma ou algumas pessoas, mas sim de um grupo, que seja coeso e participativo. Segundo a autora, sua pesquisa "se desenvolveu mediante a realização do curso 'A Gestão Escolar da Formação Continuada de Professores em Serviços - Escolas de Uberaba - MG', de abril a dezembro de 2005", sendo que este "[...] pretendeu ser um apoio para se elaborar a proposta de cada escola e a proposta municipal de Formação Continuada de Professores em Serviços [...]" (UNIUBE-5, 2006, p. 125). Contudo, a própria pesquisadora não coloca a concepção adotada em sua pesquisa como sendo a ideal, mas uma ampliação de olhares.

Em um fragmento se encontra o cluster "reflexão sobre a prática" 
da perspectiva da racionalidade prática com a "formação continuada de professores em serviço", promovendo, diante do enunciado, uma aproximação com a abordagem de formação com base no intelectual crítico.

A pesquisadora, aqui, o utilizou na acepção da expressão, pensar sobre algo que, como professores, fazem cotidianamente, e não com a visão de coletivo como promotora de uma formação política e transformadora, como aborda a perspectiva.

Outro cluster referente à perspectiva de formação por coletivos é "formação em serviço", utilizado nas pesquisas analisadas como aquela realizada no próprio local de trabalho. Diferencia-se da ideia abordada por teóricos que definem a formação em serviço como aquela destinada ao professorado que não possui habilitação específica para atuarem como professores e, mesmo assim, exerce a docência e tem essa formação paralelamente à execução de sua rotina de trabalho. Exemplificamos esse fato com o Projeto Veredas (Formação Superior de Professores) ${ }^{6}$, em Minas Gerais, o Formação Universitária ${ }^{7}$ (PEC), em São Paulo, e atualmente, os cursos oferecidos pela Plataforma Paulo Freire, em nível nacional.

O emprego de "formação em serviço" denota um sentido diferente de sua significação no âmbito da abordagem de formação por coletivos. O significado social dessa abordagem se refere à valorização dos professores e leva à conscientização e transformação da realidade de forma coletiva.

O sentido atribuído ao contexto dos enunciados se encontra descolado da construção do significado social da palavra, como a importância da formação em serviço como suplemento de uma aprendizagem específica e inexistente na formação inicial (UFG-1, 2008) e a formação em serviço aliada à competência e aperfeiçoamento, também vista como uma formação continuada no local de trabalho valorizando o cotidiano (UNIUBE-1, 2003).

6 Projeto Veredas tinha o objetivo de formar, em nível superior, em serviço e a distância, 15.000 professores das redes públicas estadual e municipal, de forma organizada e articulada pela SEE/MG, visando a garantir as competências, habilidades, valores éticos e morais requeridos ao novo padrão de sociabilidade (OLIVEIRA, 2008).

7 O programa Formação Universitária da PUC-SP (PEC) foi um projeto especial de formação docente que licenciou em Pedagogia os professores em efetivo exercício na rede pública estadual paulista, buscando garantir a melhoria da qualidade de ensino, redimensionar os padrões de gestão e transformar a realidade educacional paulista (CARNEIRO, 2005). 
A formação em serviço não possui uma linearidade; todos ensinam e todos aprendem, ou seja, todos os envolvidos são formados a partir de um movimento que solidifica o grupo e promove a tomada de decisões de forma consciente.

As práticas propostas pelos trabalhos em que ocorreram os clusters "formação continuada de professores em serviço" e "formação em serviço" interviram em seu campo investigativo promovendo cursos, grupo de estudos e oficinas, a partir de uma problemática oriunda do próprio contexto dos sujeitos envolvidos.

Nos trabalhos que apresentaram esses clusters estava presente a preocupação dos pesquisadores sobre os limites da perspectiva de formação por coletivos, pois os sujeitos envolvidos possuem experiências pouco positivas em relação à formação em serviço.

\section{Considerações}

A intencionalidade da pesquisa foi a de analisar como os clusters referentes às perspectivas de formação de professores foram empregados nas pesquisas analisadas, a fim de percebermos o sentido dado à significação das palavras.

Os clusters referentes às perspectivas de formação presentes nos trabalhos analisados foram utilizados, muitas vezes, com certa descontextualização, sem a preocupação de servir como aporte teórico, quer dizer, foram empregadas com outras denotações, não relacionando esses clusters, impressos na área educacional, às teorias. Ou seja, os sentidos a eles atribuídos, muitas vezes, não coincidiram aos seus significados sociais, quando compreendidos no interior das abordagens teóricas a eles associados.

A relação estabelecida entre as palavras e os sentidos que produzimos é a expressão de nosso pensamento, declarado em forma de fala escrita ou oral. O que registramos em nossas atividades escritas são resultados desses relacionamentos, muitas vezes apresentados com alguns vícios, outras vezes mais centrados e equilibrados, dependendo de como apreendemos o significado das palavras e como atribuímos sentidos a elas. 
A forma como foram empregados os clusters referentes às perspectivas indica uma alternância entre o significado lexical e o significado e sentido da palavra no contexto de uma concepção, ora ligada a uma, ora a mais de uma no mesmo trabalho, de acordo com os autores que a sustentaram e com as práticas formativas propostas como intervenção.

Valendo-nos dos dados obtidos, percebemos como os teóricos das concepções analisadas vêm sendo utilizados, e é notável a presença de diversos deles se apresentando como suporte de um pensamento alheio, ou ainda, a empregabilidade de vários autores em uma única pesquisa como forma de fundamentá-la, mas, muitas vezes, autores de perspectivas de fundamentação teórica e epistemológicas diferentes.

Seguindo nessa análise, podemos dizer que existe diferentes concepções nos trabalhos analisados, não estando fundamentados numa única perspectiva, o que a diversificada utilização de filiações teóricas assim anuncia. Uma pesquisa solidificada em uma concepção apresenta um arcabouço teórico referente a ela, quando muito, a utilização de outros para promoção de críticas em casos específicos e não aleatórios.

O apresentado pelo corpus de estudo não indica isso, mas sim um quadro, de certa forma preocupante, pois existe uma diversidade de bases teórico-metodológicas e epistemológicas não congruentes com a linha teórica dos autores utilizados e as práticas formativas efetivadas.

Assim, muitos dos trabalhos, pelas questões aqui apontadas, pouco contribuem com avanços teóricos significativos, principalmente pela ausência de autoria nos trabalhos; ficam mais na repetição do já elaborado e, como mencionado, muitas vezes com aportes nem sempre dialogáveis do ponto de vista epistemológico e, o que pode parecer pior, como sendo de uma mesma perspectiva.

Elencamos alguns dos autores mais citados, direta ou indiretamente, que compuseram o rol das pesquisas: Tardif, Nóvoa, Perrenoud, Schön, Zeichner, Pérez Gomez, Dewey, Stenhouse, Habermas, McLaren, Giroux, Gramsci, Alvarado Prada, Freire, Makarenko, Brandão, Vygotski, Duarte, Leontiev, Libâneo, Nuñez, Mazzeu e Saviani.

Esses autores ligados a diferentes perspectivas de formação, como a racionalidade prática, a intelectual-crítico, a formação por coletivos, a 
histórico-cultural e a histórico-crítica, cada um dos quais fundamentando perspectivas específicas, estão presentes nas práticas de formação propostas pelos pesquisadores.

As práticas de formação delineadas nas pesquisas de intervenção foram realizadas de diversas maneiras: curso, grupo de estudo, oficinas, encontros mensais, acompanhamento e observação participante. Essas nomenclaturas foram dadas pelos próprios pesquisadores.

A proposta de curso foi realizada em dois trabalhos: um na UFG e outro na UNIUBE. No primeiro, a pesquisadora propôs um curso de capacitação para professores de classe hospitalar baseado na teoria de Balint, com certificação expedida ao final do curso. No segundo, a pesquisadora promoveu um curso de gestão escolar para gestores que seriam multiplicadores na rede municipal de ensino e, ao final dele, o grupo elaborou uma proposta institucional de formação continuada para os professores do município.

No trabalho da UFU, a proposta foi a realização de encontros mensais com duração preestabelecida visando a discutir/estudar temas voltados à educação infantil e, em concomitância aos encontros, a pesquisadora acompanhou em serviço sujeitos da pesquisa, a saber, as educadoras infantis.

Em outro trabalho da mesma instituição, a proposta foi a de acompanhamento e observação participante do pesquisador com alunos de licenciatura em Matemática que estavam realizando estágio supervisionado em escola pública de educação básica.

A proposta de grupo de estudo está presente em dois trabalhos da UNIUBE. Um deles se ateve em estudar as práticas educativas sobre a avaliação da aprendizagem com professores da educação básica de uma escola particular. O outro propôs estudar sobre os esportes coletivos com os alunos do curso de graduação em Educação Física e professores / técnicos de esportes coletivos.

A prática oferecida a partir de oficinas foi empregada em três pesquisas da UNIUBE com sujeitos diferentes: em uma delas foi realizada com professores-instrutores de ensino profissionalizante, pois já estava inserida na proposta institucional; em outra, foi realizada com alunos-docentes do curso de Pedagogia da própria instituição, com foco nas práticas 
educativas e as influências do curso em sua atuação profissional; a terceira foi realizada com professoras de duas escolas de educação básica, sendo uma de assentamento rural e a outra da área urbana, focando a avaliação da aprendizagem, pluralidade cultural e a relação família-escola.

No entanto, é necessário salientar que todos os trabalhos analisados se mostraram semelhantes em alguns aspectos: 1) existência de limites e possibilidades de formação; 2) objetivaram transformações das práticas existentes, com possibilidade de alcançar autonomia; 3) intervenção in locus, ou seja, no local de trabalho; 4) consideraram o grupo de pessoas envolvidas na pesquisa, partindo do contexto.

Esses aspectos contemplam pressupostos básicos de grande parte das perspectivas de formação de professores, não se restringindo a uma ou a outra. Entretanto, percebemos que os autores admitem haver limites a serem superados ao trabalhar com um coletivo de pessoas, sendo necessário superar alguns entraves, mas não deixam de acreditar nas possibilidades de formação que proporcionaram.

A partir da apreensão do sentido e do significado pela pesquisadora, as diretrizes de análises dos dados, erigidas a partir desses pressupostos, levaram-nos aos resultados, que ora os constituímos em unidades de significação, assim dispostos: 1) prevalência de abordagem; 2) diálogos desenvolvidos com teóricos; 3) clusters utilizados.

Em relação ao que prevalece em termos de abordagem no corpus de estudo, encontra-se a perspectiva de formação com base na racionalidade prática. Os índices percentuais da quantidade de vezes em que os clusters aparecem como aderência à perspectiva em relação ao quantitativo geral de aparições no corpus são assim representados: "reflexão sobre a prática" com 90,90\% e "professor reflexivo" com 100\%.

Esses índices indicam que a concepção predominante nas pesquisas analisadas, aliada à utilização de teóricos e mediante as práticas formativas propostas, revela uma aderência a essa perspectiva.

Acreditamos que esses dados se mostrem nesse formato pelo fato de que autores pertencentes a essa perspectiva, como Schön, Pèrez Gómez, Zeichner, Nóvoa, Dewey, entre outros, foram assumidos quase que inquestionavelmente pela academia brasileira nas décadas de 1970- 
1990, a partir de suas teorias que foram difundidas no meio social, sem, contudo, deixar de mencionar o viés ideológico dessa entrada no Brasil.

Os teóricos utilizados nessas pesquisas, nem sempre são filiados a essa perspectiva de formação, havendo sim a presença de outros que não aderem a essa perspectiva. Sobre esse dado, podemos analisá-lo no sentido de que os pesquisadores elegem os teóricos para dialogarem a partir não necessariamente de uma base epistemológica coincidente com a sua concepção, mas sim por tratarem de assuntos próximos a acepção do cluster em relevo, do que realmente por suas filiações teóricas.

Em relação aos diálogos desenvolvidos com os teóricos no conteúdo das pesquisas, percebemos em algumas delas, uma cisão entre significado e sentido, ou seja, os pesquisadores não aderem aos teóricos pela sua base epistemológica e se distanciam do propósito de suas teorias, ou, às vezes, os citam, assim como as abordagens, para referendar alguma ideia ou conceito não por coerência ou aderência à perspectiva.

Esse distanciamento entre o posicionamento dos autores das pesquisas e a base epistemológica dos teóricos é preocupante. É indicativo de que as pesquisas de intervenção estejam se realizando sem uma base teórica sólida e epistemológica clara, com sustentação em teóricos filiados a ela; e, ao contrário disso, presenciamos, em alguns trabalhos, o uso de autores de maneira indiscriminada.

A postura assumida pelos pesquisadores nesses trabalhos denota a fragilidade com que vêm sendo construídas as pesquisas de intervenção que propõem práticas formativas a professores.

Essa fragilidade em suporte teórico fica explícita quando, em determinados momentos, os pesquisadores estabelecem diálogos com autores diversos sob o mesmo contexto, sendo esses oriundos de bases epistemológicas distintas.

Isso fica evidente quando os pesquisadores utilizam citações de vários teóricos para fundamentar seus trabalhos, ficando explicitamente notório dentro do corpus de estudo a quantidade de teóricos citados apenas uma única vez; e, outros, em quantidades diversas, mas que não compartilham as mesmas ideias; logo, eleva-se a valorização da quantidade e não da qualidade dos diálogos. 
Pela análise dos clusters utilizados, percebemos que muitas vezes aparecem em citações diretas e indiretas, havendo presença de citações de citações, em que a autoria do pesquisador não é transparente, sempre se coloca à sombra dos teóricos, indicando ausência de posicionamentos claros diante da problemática de pesquisa.

A falta de autoria em algumas pesquisas indica a ausência de posicionamentos críticos, tendo em vista que os clusters pouco aparecem com essa conotação, levando-nos a acreditar que os autores, durante o seu processo formativo que foi constituído sob uma determinada conjuntura social, não foram oportunizados a construir uma postura crítica em relação à sua realidade, de maneira que pudessem, por meio das práticas formativas a que estavam expostos, desenvolver sua criticidade.

Como consequência, entendemos que a quantidade de citações diretas e indiretas, que muitas vezes se encontram deslocadas de seu contexto original, vêm fazendo parte de um diálogo que nem sempre suportam.

Isso é perceptível no modo como os clusters são utilizados pelos pesquisadores, isto é, não apresentam contraposições às ideias, mas sim conformações, concordâncias, que, em certos trabalhos, não passam de aglomerados de excertos de obras.

Diante de nossas análises, eles estão, em certas pesquisas, sendo utilizados não em consonância à significação social, mas apresentados com outros sentidos. Dessa forma, há distanciamento entre o significado do cluster e o sentido atribuído pelo pesquisador em sua pesquisa.

A coincidência ou o distanciamento entre o significado apropriado referente ao cluster e o sentido atribuído a ele, presente nos trabalhos analisados, permite inferir que o contexto social gera significações contundentes em relação ao significado dos clusters, ligando-os como pertencentes a uma determinada perspectiva de formação.

Entretanto, esse mesmo contexto propaga que determinados clusters são pertencentes a certas perspectivas de formação e, diante dessa significação social, quando eles aparecem sob outras acepções, não é aceito pelo meio que os constituiu, porém, um cluster é indicativo de uma abordagem não somente por um significado, mas também pelas relações estabelecidas no contexto em que os pesquisadores utilizam. 
Passagens assim estão presentes no corpus de estudo, em que o cluster pertencente a uma perspectiva de formação, que foi construído socialmente, está orientada por um sentido atribuído em conformidade a outro contexto.

Em certos momentos, clusters de diferentes perspectivas se encontram próximos um do outro, denotando haver falta de discernimento sobre as origens epistemológicas diante de sua utilização.

Os autores das pesquisas se mostram alheios ao regramento com a utilização dos clusters, não se atendo a pertencimentos propagados em significações sociais, mas tão somente, em alguns casos, pela própria acepção que possuem.

Essa apresentação concernente aos clusters nos leva a refletir sobre a restrição do meio social, nesse caso o acadêmico, em limitar a criatividade do pesquisador no momento de trabalhar as palavras para materializar seu pensamento, ficando ele preso a significações sociais que restringem e até mesmo excluem do processo a criação de novas formas de escrita, ou a criação de novas palavras ou definições, ficando, assim, presos ao que é pré-determinado pelo meio social.

Assim, os pesquisadores no processo de significação, atribuem um sentido concordante, e aceitam esses limites, cristalizando o que foi constituído como verdadeiro e, logo, não criticam os clusters solidificados pelo contexto social como sendo pertencentes a perspectivas. Além disso, não criam novas maneiras de expressarem seus pensamentos no âmbito de suas pesquisas, ficando presos ao que é determinado pelas práticas sociais em vigor.

Os apontamentos conclusivos deste estudo são reveladores da situação em que se encontram as produções acadêmicas em nível de pós-graduação, em especial, teses e dissertações, defendidas na região Centro-Oeste.

A aprendizagem da docência desencadeada por processos de formação de professores está atrelada às qualidades dos instrumentos e signos que medeiam os processos formativos vividos, depende dos conteúdos, meios e métodos propostos.

Os processos mediacionais são definidores da apropriação do 
significado social e da atribuição de sentido constituída nos processos de formação e prática docente, passíveis de humanizar o professor e o formador ou de aliená-los.

Temos certeza de que há muito a ser descoberto, discutido e analisado com base nos resultados apresentados. Esperamos, com isso, que os dados aqui pautados se constituam em elementos motivadores de outras pesquisas.

Este estudo se apresenta como a ponta de um iceberg ou o microcosmo do universo das produções acadêmicas brasileiras e, para desvendá-lo de forma minuciosa, é preciso trilhar por caminhos nem sempre lineares, pois significado e sentido são conceitos distintos que não se sobrepõem um ao outro, mas se constituem em unidade e são reveladores da consciência humana. 


\section{Referências}

ALVARADO PRADA, Luis Eduardo. Pesquisa coletiva na formação de professores. Revista de Educação Pública, v. 15, n. 28, p. 99-118, maio/ago. 2006.

CARNEIRO, Maria Ângela Barbato. O PEC - formação universitária: a complexidade de um processo. Revista PUCVIVA, n. 24, jul/set. 2005. Disponível em: <http:/ / www.apropucsp.org.br/ revista/r24_r03.htm>. Acesso: 7 fev. 2011.

MARX, Karl; ENGELS, Friedrich. A ideologia alemã. Tradução de José Carlos Bruni e Marco Aurélio Nogueira. São Paulo: Hucitec, 1989.

OLIVEIRA, Valéria de Freitas. A escola, espaço coletivo de formação continuada de professores em serviço: limites e possibilidades. 2006. 200 f. Dissertação (Mestrado em Educação) - Faculdade de Educação, Universidade de Uberaba, Uberaba, 2006.

OLIVEIRA, Daniela Motta. Formação de professores em nível superior: o projeto veredas e a nova sociabilidade do capital. In: REUNIÃO ANUAL DA ASSOCIAÇÃO NACIONAL DE PÓSGRADUAÇÃO E PESQUISA EM EDUCAÇÃO - ANPED, 31., 2008, Caxambú. Constiuição Brasileira, Direitos Humanos e Educação. Rio de Janeiro: ANPED, 2008. p. 1-5. Disponível em: <http:/ / www.anped. org.br/reunioes/31ra/1trabalho/GT11-4079--Int.pdf>. Acesso em: 13 ago. 2011.

SMOLKA, Ana Luiza Bustamante; LAPLANE, Adriana Lia Friszman. Processos de cultura e internalização. In: Coleção Memória da Pedagogia. Suplemento Especial. Viver Mente e Cérebro. São Paulo: Duetto, v. 2, p. 76-83, 2005.

Recebido: 17/02/2013

Aprovado: 07/05/2013 